\title{
Percent Recovered Infinity Observed Normalized by Surface Area
}

National Cancer Institute

\section{Source}

National Cancer Institute. Percent Recovered Infinity Observed Normalized by Surface

Area. NCl Thesaurus. Code C112390.

The percentage of the recovered administered dose extrapolated to infinity, calculated using the observed value of the last non-zero concentration, divided by the surface area. 